\title{
Assessing Real Time GPS Asset Tracking for Timber Haulage
}

\author{
Ger J. Devlin* and Kevin McDonnell
}

Biosystems Engineering Department, University College Dublin, Belfield, Dublin 4, Ireland

\begin{abstract}
This paper discusses the background to real-time GPS asset tracking in the context of 1) monitoring moving vehicles, 2) the content of the GPS data that is provided as part of the 2 systems that were tested, 3) the theory behind the installation of such tracking systems in terms of GPS, GPRS and internet communications and finally, 4) the assessment of the economic benefits of both systems is also discussed. This involved the installation of 2 different GPS asset tracking providers, Bluetree and Fleetmatics onto 2 timber haulage trucks - an articulated Iveco Stralis $5306 * 2$ tractor unit with tri-axle road friendly air suspension flat bed trailer with a design gross vehicle weight (d.g.v.w.) equal to $44000 \mathrm{~kg}$. The Scania 124 (400) was a rigid (3 axle) + trailer (3 axle) + crane combination with an equivalent d.g.v.w. of $44000 \mathrm{~kg}$.
\end{abstract}

Keywords: Real-time GPS, asset tracking, timber haulage, vehicle reports, engine diagnostics, economic analysis.

\section{INTRODUCTION}

The rising amount of timber transported on the public road network across Ireland will present major challenges to the Irish road network in the coming years. The potential production of roundwood from the forests of Ireland will reach 5 million $\mathrm{m}^{3}$ per annum by the year 2015 [1]. The majority of this harvested timber will be softwood. Coillte (Irish Forestry Board) will remain the dominant supplier, but it is predicted that their market share will drop from $84 \%$ in 2001 to $66 \%$ by the year 2015 . The private forest sector market share will rise to $23 \%$ and the Northern Ireland forest sector will remain constant at 11\% [2]. Road transport will remain the most important mode of timber transport in Ireland, forming a substantial part of the timber industry's raw material costs and having a major influence on the sector's overall economic performance and competitiveness [2]. Mintsis et al. 2004 [3] discusses the applications of GPS technology for road and rail mapping and integrating the captured data for GIS thematic maps to be produced. The billion dollar information sector is becoming inextricably linked to the transportation sector in terms of real-time spatial, attribute and engine diagnostic data. The real challenge for Ireland's transport sector is to incorporate and take advantage of the potential of integrated GPS/GIS systems. According to Zito et al. 1995 [4], the use of GPS real-time data is crucial in order to model and simulate route planning within the GIS. By modeling position, speed, direction and travel time, it will be possible to pre-plan and optimize routes for scheduling scenarios. The GIS can be used to simulate realistic travel speeds and times by implementing impedances on different classes of roads to reflect traffic flow situations [5]. Routing simulations using a 0/1 integer linear programme developed by Murphy, 2003 [6] for 2 New Zealand forest companies found that truck fleet size could be reduced by 25 to $50 \%$ was possible. In a world of increasing running costs, reducing the sizes of truck

\footnotetext{
*Address correspondence to this author at the Biosystems Engineering Department, University College Dublin, Belfield, Dublin 4, Ireland; Tel: +353 1716 7418; Fax:+353 1716 7415; E-mail: ger.devlin@ucd.ie
}

fleets and being able to carry out the same work through simple route optimizing is a worthwhile research project that can be fully implemented for all concerned [7].

Annually, Coillte must inform the respective Local Authorities of the sites that they intend to harvest during the coming year and the roads that they intend to use as an access route. Planning licences are needed before any timber extraction can be carried out. Depending on their location, public roads are the responsibility of the National Roads Authority (NRA) or the Local Authorities. It is an offence to damage public roads under the Road Act 1993 [8]. Examination of timber haulage weight records showed that $20 \%$ of all truck axle configurations are in excess of 20 $000 \mathrm{~kg}$. Added to this is the fact that $60 \%$ are exceeding the $44000 \mathrm{~kg}$, the design gross vehicle weight (d.g.v.w.) for 6 axle configuration. For example, in Scotland, it is recognised that the rapidly increasing timber harvest is going to have significant impact on the rural road network, namely regional and third class roads. As a result of this the Scottish Forestry Commission and a number of local authorities have developed agreed routes, which are selected to keep timber traffic off the most vulnerable roads by directing it along stronger and safer routes [9]. Scotland has a timber production forecast of 2.95 million $\mathrm{m}^{3}$ for the year April 2004 to March 2005, compared with 3.25 million $\mathrm{m}^{3}$ for Ireland in the same period. Scotland has a forest cover of 1.33 million hectares compared to Ireland's 0.659 million hectares, yet the amount of harvested timber transported on Irish roads is far greater than that of Scotland. Coillte in conjunction with every Local Authority have also developed and agreed routes for timber extraction in an effort to reduce the cost of road repair and maintenance.

GIS technology has already successfully been incorporated into the Irish forest industry dealing with the inventory mapping, harvest scheduling and planning. This has led to the development of the GIS based planning tool called FIPS (Forest Inventory and Planning System). FIPS is currently one of the largest GIS systems in Ireland and the UK. FIPS' development was led by Coillte and included the National Remote Sensing Centre in the UK and the Space 
Applications Institute of the EU's joint research centre in Italy. Its development was through innovative technologies such as remote sensing, Ordnance Survey maps and aerial photography. However, little work has been undertaken concerning the pre - planning and scheduling within the haulage sector in Ireland as well as the real-time GPS tracking of the actual timber haulage trucks [10].

Several research projects have been undertaken in an attempt to optimise the timber extraction routes over a sample road network so that timber transportation could be routed to the nearest higher class roads to minimise the damage to the peat based forest access roads [4]. This would effectively reduce the expenses of road maintenance [11]. Martin et al. (2001) [12] incorporated GIS technology to research the evaluation of timber extraction routes. The results found that the maintenance costs of the optimum routes of $10,969 \$ / \mathrm{km}$ was in fact higher than the maintenance costs of the actual travelled haulage routes by $332 \$ / \mathrm{km}$. This would suggest that the transport of timber should be routed towards the higher class of roads and not necessarily to the optimum route (shortest route), to minimise the road maintenance costs. Arvidsson et al. (1998) [13] predicted that by attempting to optimise the route travelled for timber haulage trucks in Sweden, the forestry sector could reduce the percentage of empty return journeys by $22 \%$, which is equivalent to an annual saving of approximately US\$ 12.5 million. This in turn implies a possible elimination of 20 million kilometres of empty return journeys, resulting in a reduction of 6.5 million litres of consumed diesel and a corresponding 5\% reduction in harmful $\mathrm{C} 02$ exhaust emissions. It has been previously regarded that using optimised routes in the north of Sweden is limited since the flow of timber was thought to be only one way, simply because the largest mills are located on or near the coast. Forsberg, (2003) [14] has concluded, however, that by using optimised routes in the north of Sweden, could have in fact reduce direct costs by $5 \%$ and the number of empty return journeys by $24 \%$.

A similar type of routing model has been developed in Wales [9]. This project is attempting to model the flows of timber from Welsh forests across the road network from now until 2015 and try to predict any changes in the movement of timber across different classes of roads. The project uses ESRI's ArcGIS software for mapping both the Welsh public road network and forest road network. The Network Analyst Tool (NAT) is also used to model and predict the movement of the trucks. Frisk et al. 2005 [15] and Eriksson et al. 2003 [16] have developed forest planning tools, FlowOpt and AkarWeb respectively. These computerized decision support systems enable businesses to perform practical and efficient route planning from monthly flow planning to daily route planning to real-time dispatching to find the lowest possible haulage costs.

\section{MATERIALS AND METHODS}

\subsection{Installation of GPS Hardware}

The 2 independent GPS asset tracking providers were Bluetree and Fleetmatics. Installation of the GPS Blackbox with GPS tracker takes approximately 30 minutes to complete and is almost equivalent to the installation of a hands-free mobile phone carkit. The Blackbox and associated wiring is fixed under the dashboard on the passenger side of the truck (Fig. 1).

The GPS tracker is positioned on the outer side of the dashboard so that it becomes visible through the front windscreen. The GSM/GPRS (Global System for Mobile Communications/General Packet Radio Service) magnetic antenna is fixed to the inside of the windscreen for optimum signal strength. The FMS (Fleet Management System) cable is use to extract the engine diagnostic information such as idling time, harsh braking, kilometer per litre etc. The blue wire is the CAN_High and yellow is the CAN_Low. These must be connected into the CAN Bus from the FMS gateway on the truck's engine. The GPS Blackbox is fitted with a standard mobile phone SIM card and positional Latitude and Longitude information are recorded by the GPS and sent via the GSM/GPRS phone network to the data servers (Fig. 2). This information can then be viewed through pc/laptop and internet web browser with username and password through the login page of the asset tracker providers. The amount of updated data depends solely on the time interval required by the user. This system operated at 3 minute intervals but any time interval whatsoever can be requested and subsequently set-up by the provider in question.

\subsection{Truck Specifications}

Both Bluetree and Fleetmatics systems were fitted to 2 different axle configuration timber haulage trucks. The articulated truck was an Iveco Stralis $5306 * 2$ tractor unit with tri-axle road friendly air suspension flat bed trailer with a d.g.v.w. equal to $44000 \mathrm{~kg}$ (Fig. 3). The Scania 124 (400) was a rigid $(3$ axle $)+$ trailer $(3$ axle $)+$ crane combination with an equivalent d.g.v.w. of $44000 \mathrm{~kg}$ (Fig. 4). Even though both truck configurations have the same d.g.v.w due to the 6-axle configuration, the articulated Iveco has a higher payload weight than the Scania rigid simply because this rigid + trailer + crane combination increases the unladen weight and thus reduces the payload weight acceptable under weight legislation in Ireland. However, the idea behind the on-board crane is to offer flexibility to the driver when loading and unloading timber.

\subsection{Bluetree vs Fleetmatics}

The difference between Bluetree and Fleetmatics depends on the level of monitoring required by the company/transport manager. Both systems compare well in terms of the real-time GPS tracking that they provide. The installation and configuration of the GPS tracker plus Blackbox and GSM/GPRS antenna are effectively identical for both. Each system then provides a username and password to login to the system through an internet web browser via a pc/laptop. It is recommended that the internet connection be broadband (wireless or landline) of at least $1 \mathrm{Mb}$ download speed and $512 \mathrm{kbps}$ upload speed. While this criteria is true for effective use of the Bluetree system, it is fair to say that Fleetmatics can be operable whilst using basic dial-up internet connection at speeds of $56 \mathrm{kbps}$.

From a visual point of view, the mapping is always a concern. An Irish based company called Mapflow provide the road mapping for Fleetmatics while Microsoft Mappoint 


\section{Power/Ground/Ignition \\ Red/BlackWhite}

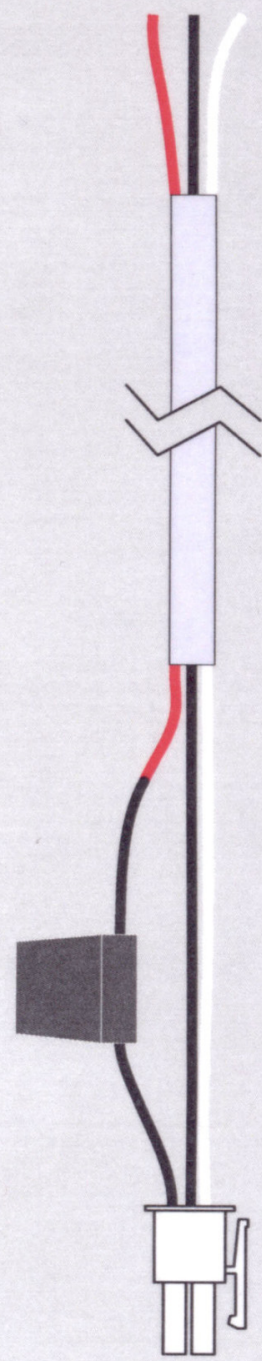

\section{FMS}

See over ...

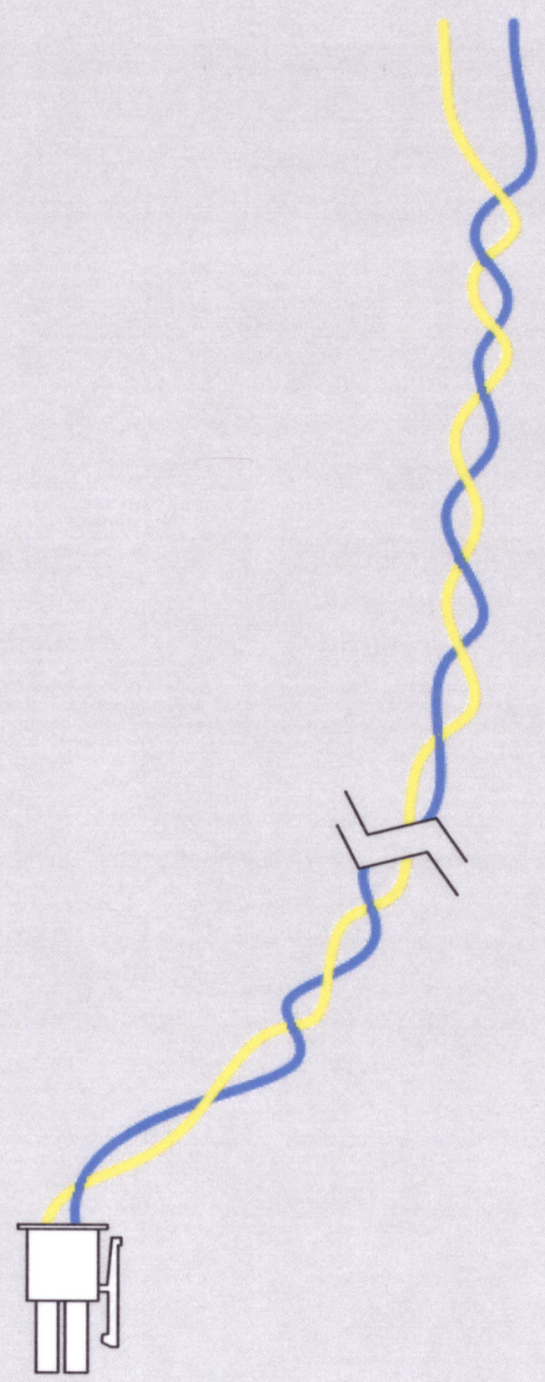

GPS

Mount horizontally

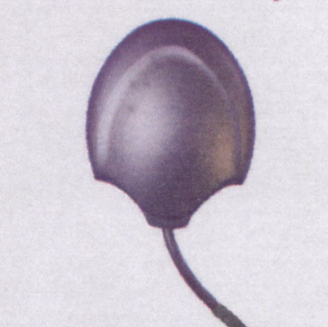

\section{GSM}

Mount vertically

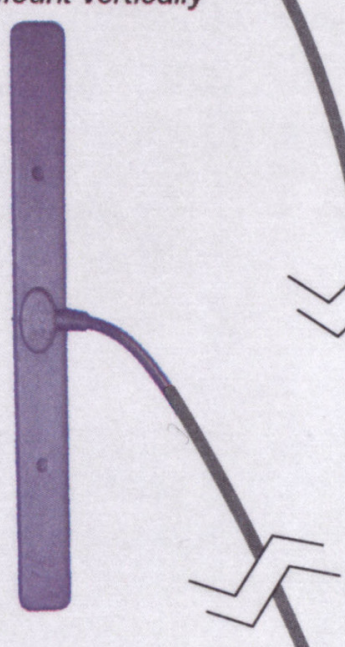

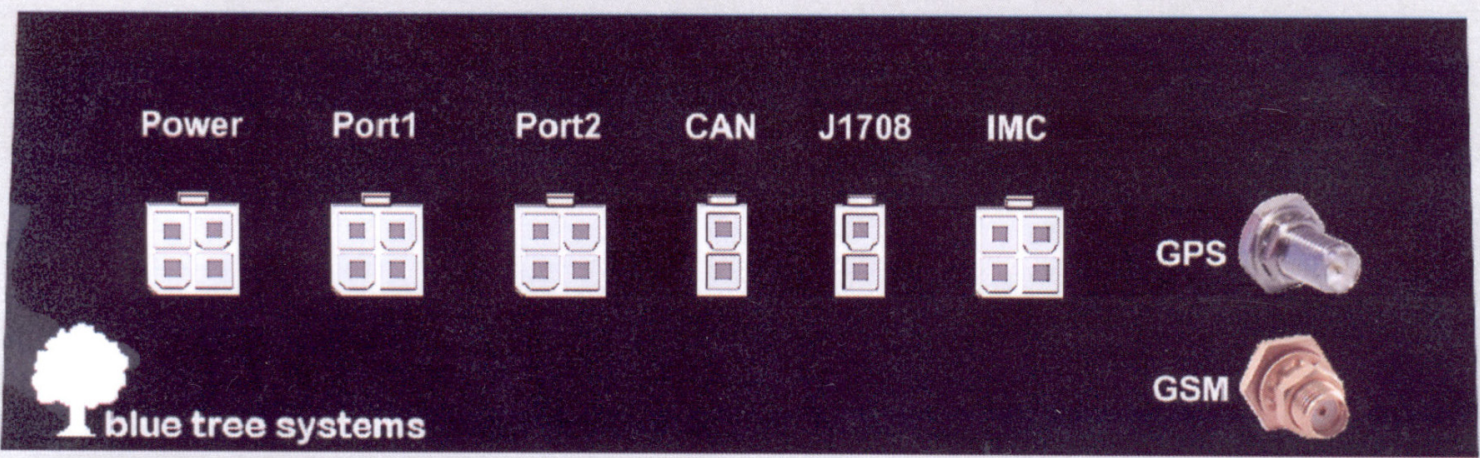

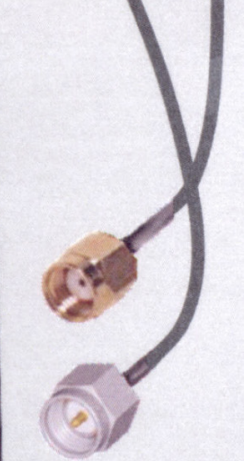

Fig. (1). Schematic of GPS Blackbox wiring from Bluetree (FMS wiring included here but this is not needed for Fleetmatics).

are the mapping providers for Bluetree. There are differences in how visually appealing the road maps look. Fleetmatics has more of a raster type look from it (Fig. 5), whereas Bluetree's map has a digital vector aspect to it and is the more favoured from the author's point of view (Fig. 6). The scales of each map can be altered to view the mapping in more detail if required, especially if trucks are traveling on lower classes of roads as opposed to motorway, national 


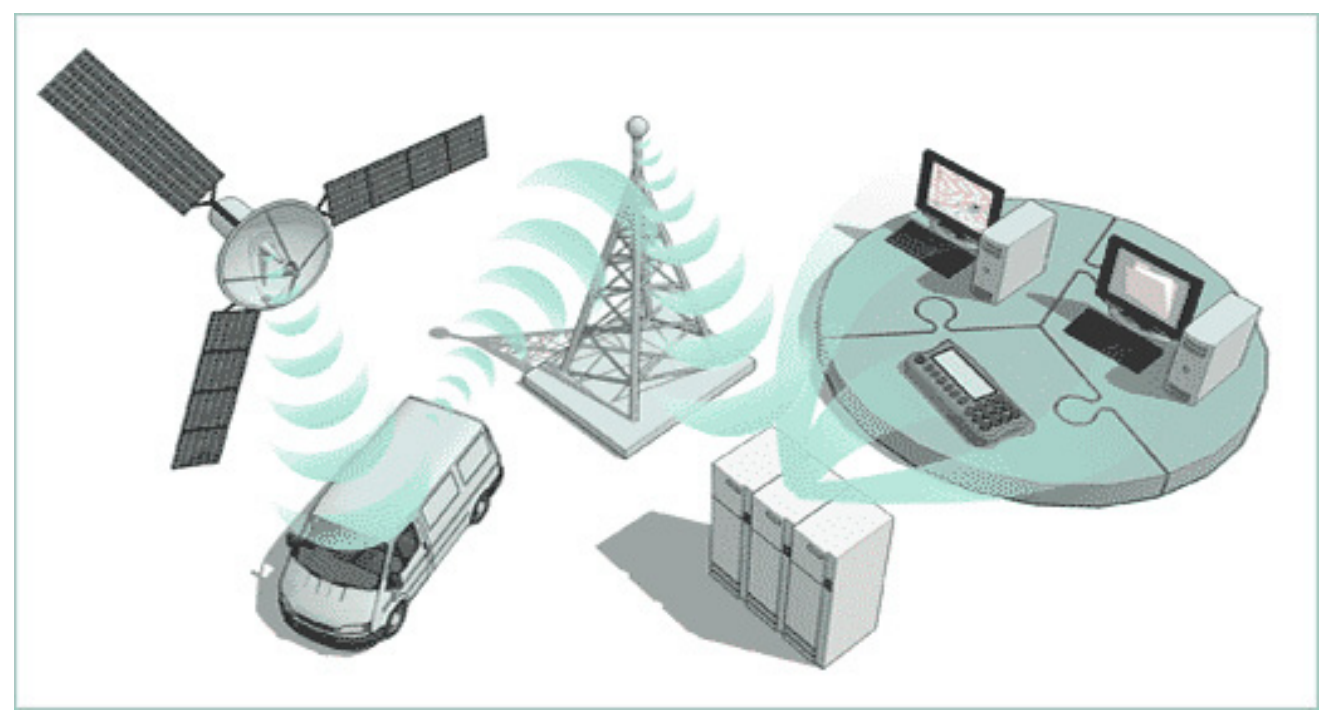

Fig. (2). Schematic showing modes of transferring GPS data from vehicle to the servers via GSM/GPRS and accessed through pc based web browser.

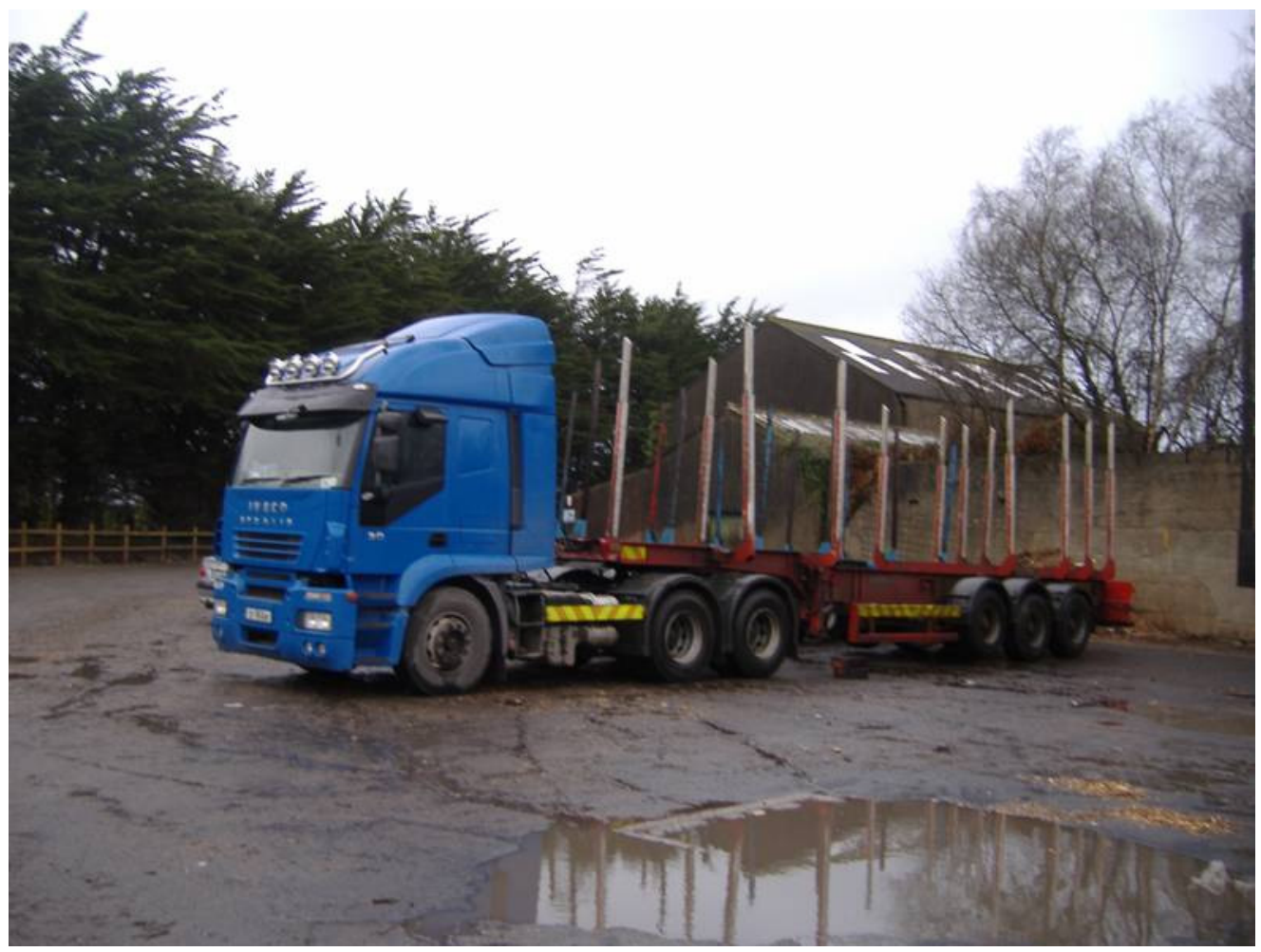

Fig. (3). Iveco Stralis 530 articulated configuration.

primary or national secondary or indeed traveling on the internal forest road network when collecting timber.

\subsection{Data Reports}

In terms of the reports directly related to the GPS location information then both systems do not differ that much, perhaps only in how the reports are presented through each system. The exact reports from Fleetmatics can be seen with the dropdown menu on the left-hand side of Fig. (5) above. The most important of these reports from an information and analysis point of view include; Daily report, Fleet daily report, Hours worked, Truck idling report, Journey idling report, Location report, Stop time report and
Vehicle activity report. In situations where drivers are paid based on each employee filling in their respective timesheets correctly and honestly at the end of each working week, the transport manager can cross reference the hours worked with these available reports and thus manage exactly each employee's wages and help eliminate false time sheets and consequently reduce the weekly wages bill. From a contracting perspective where major companies like Coillte contract the haulage of timber externally and pay contractors based on mileage bands, then each system can also be used to confirm exact distances traveled for each truck and remit payment accordingly, no more or no less. Similar reports are generated with the Bluetree system also (Fig. 7). 


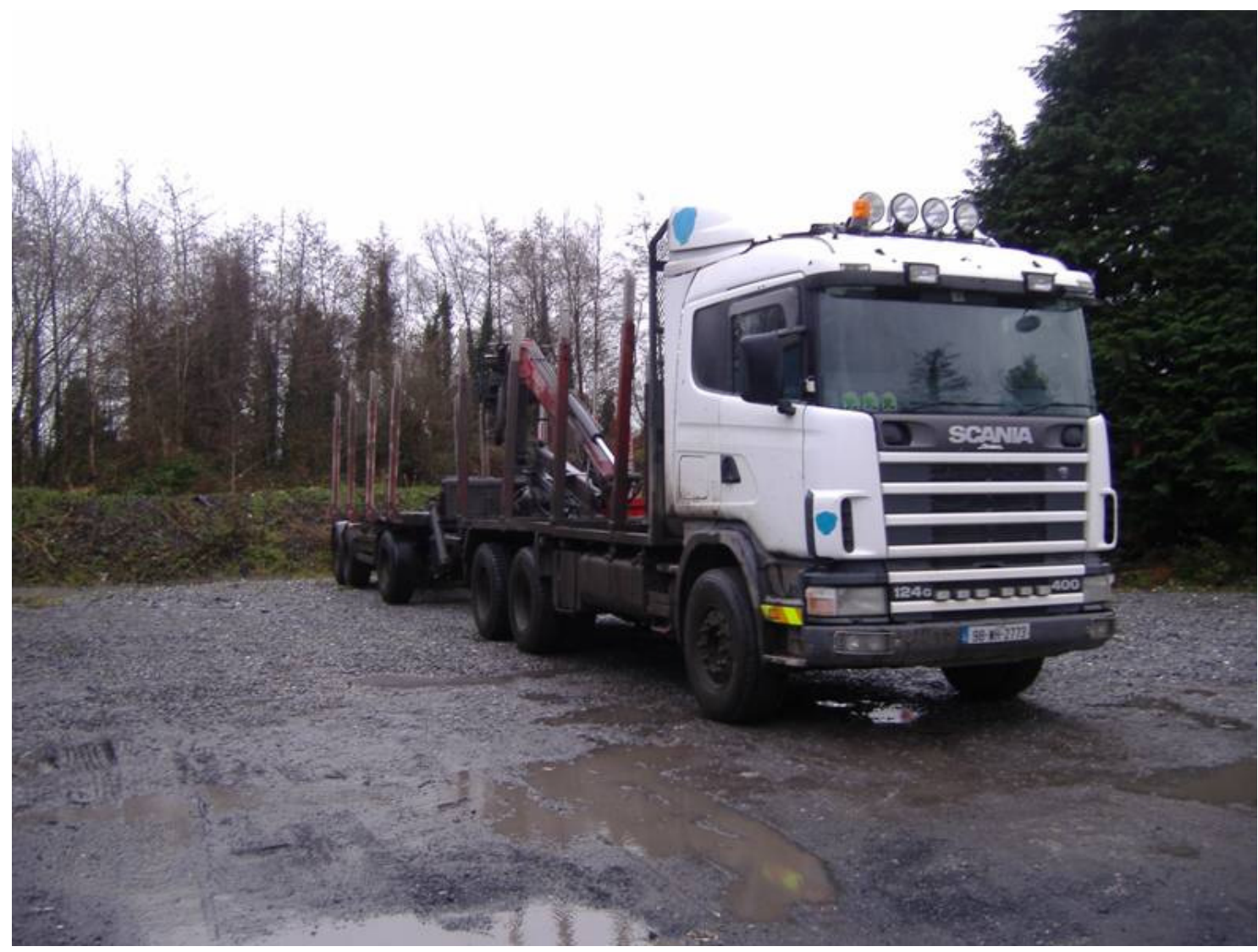

Fig. (4). Scania 124 (400) rigid + trailer + crane configuration.

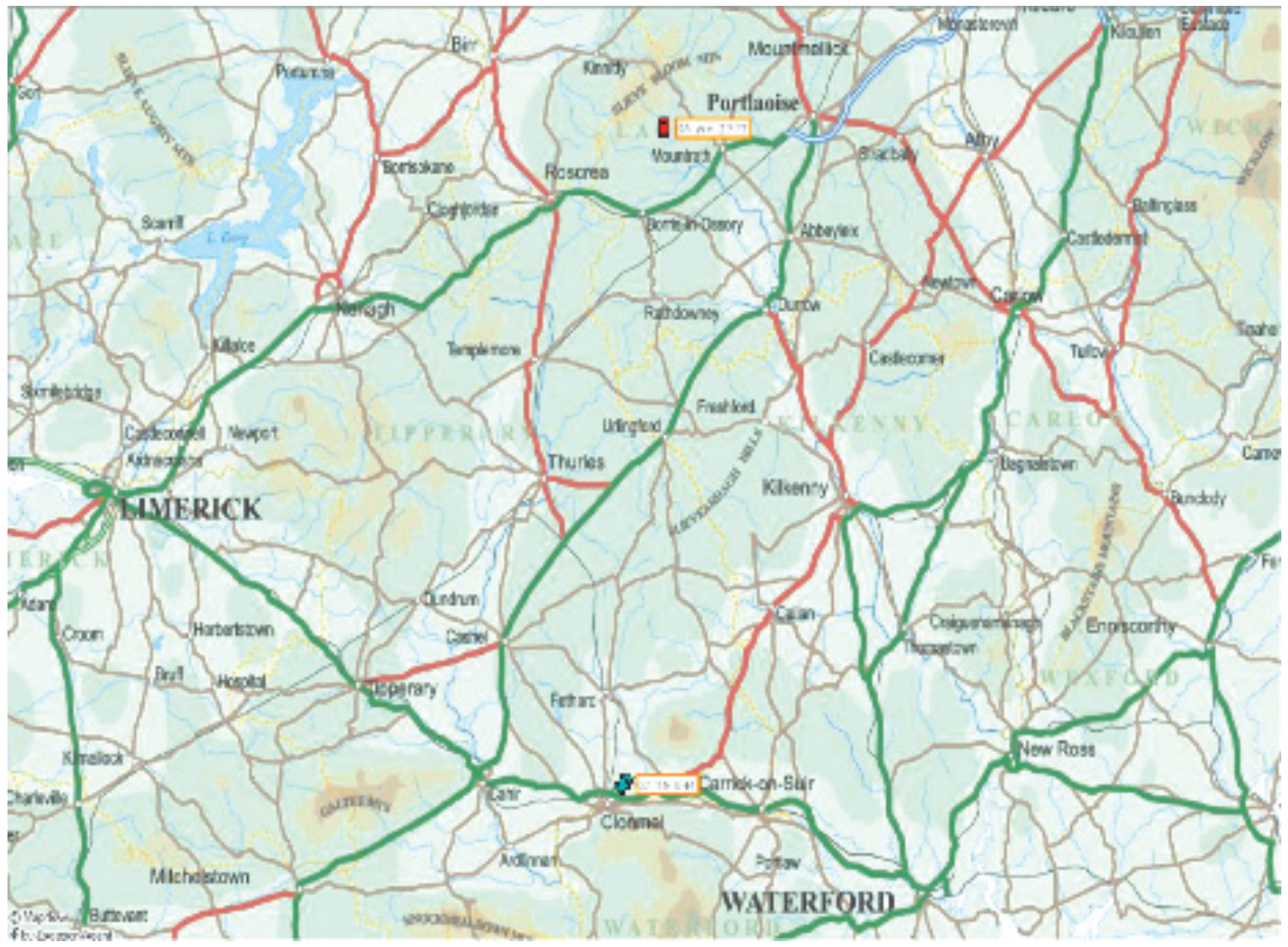

Fig. (5). Screenshot of Fleetmatics road map (showing location of both trucks). 


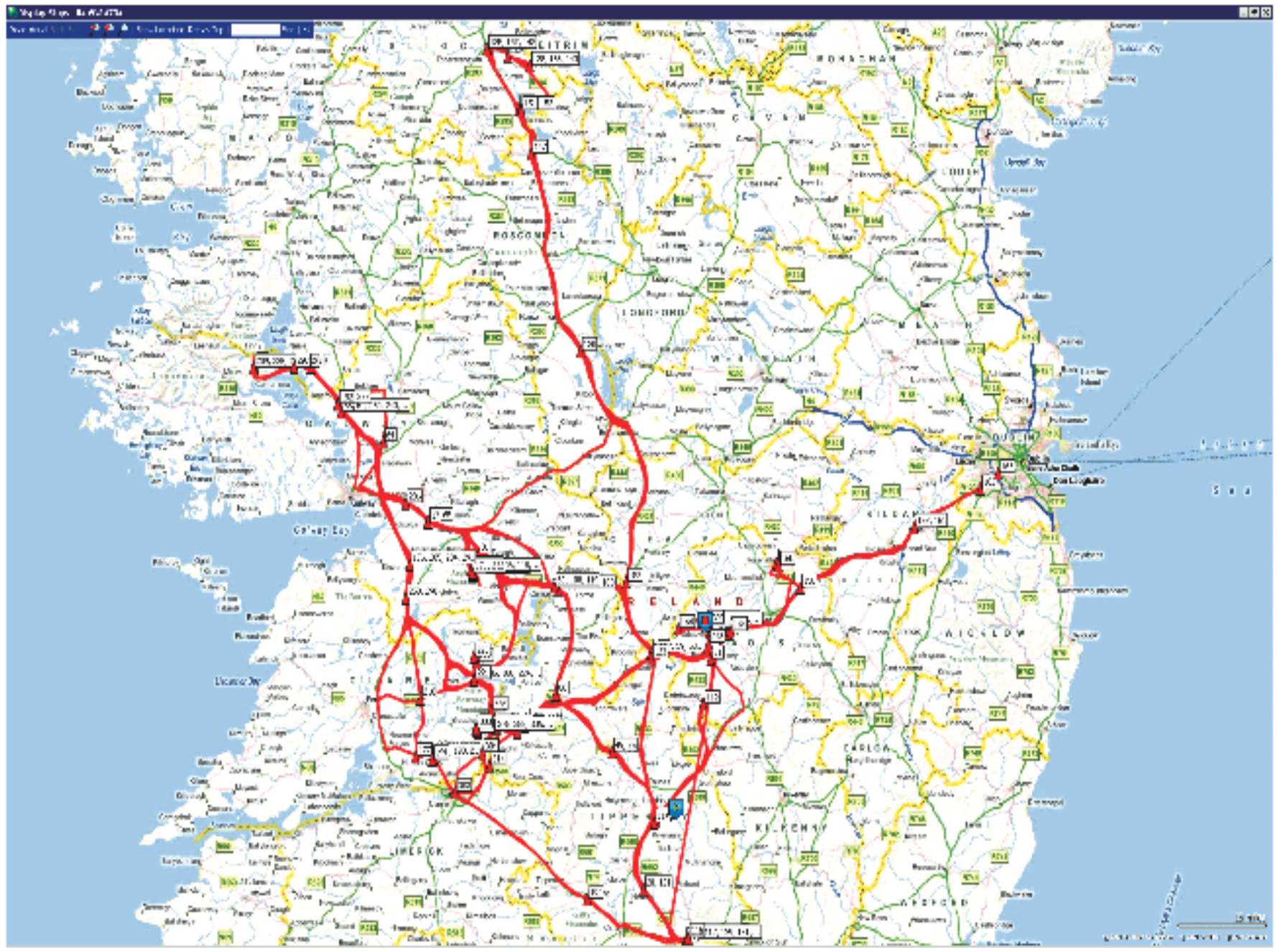

Fig. (6). Screenshot of Bluetree road map (showing travelled routes of truck).

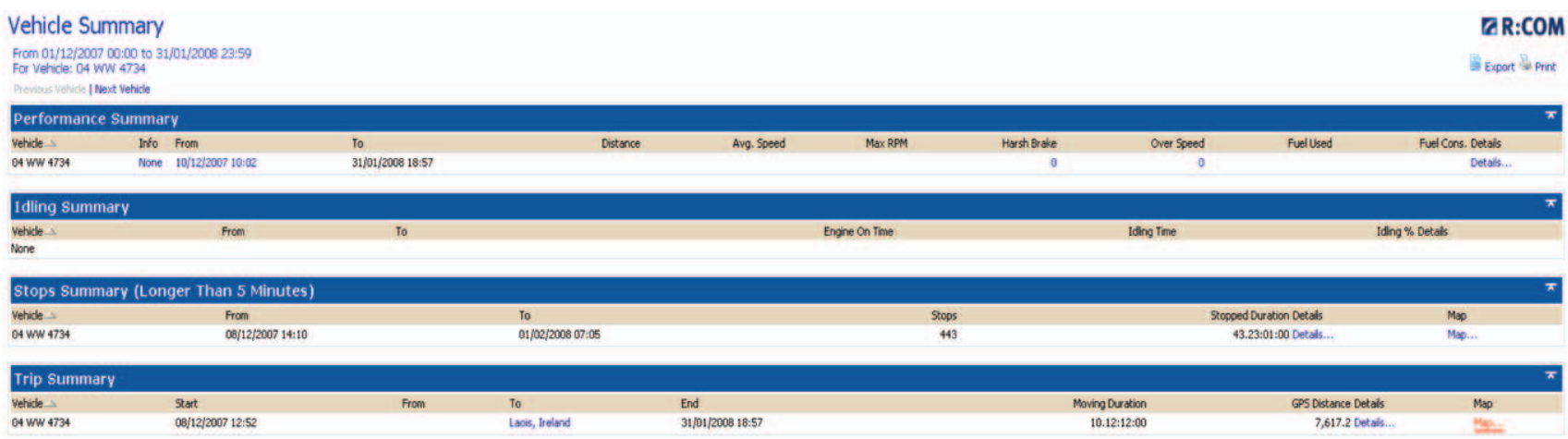

Fig. (7). Screenshot of Bluetree data report screen.

An impressive aspect to Fleetmatics is that it allows for a Route Replay, meaning that for any particular truck/vehicle the route traveled can be replayed back in real-time for any given day so as to verify the exact movements of the driver. Aswell as this, there is a mechanism for inputting values to calculate the Cost per kilometer $(\mathrm{CPK})$ and the Cost per hour $(\mathrm{CPH})$ for the entire journey/day's work. The resulting costs are directly related to the actual distance traveled and the hours worked which is in fact recorded on the system already (Fig. 8). The idea behind the CPK and CPH of course is for 


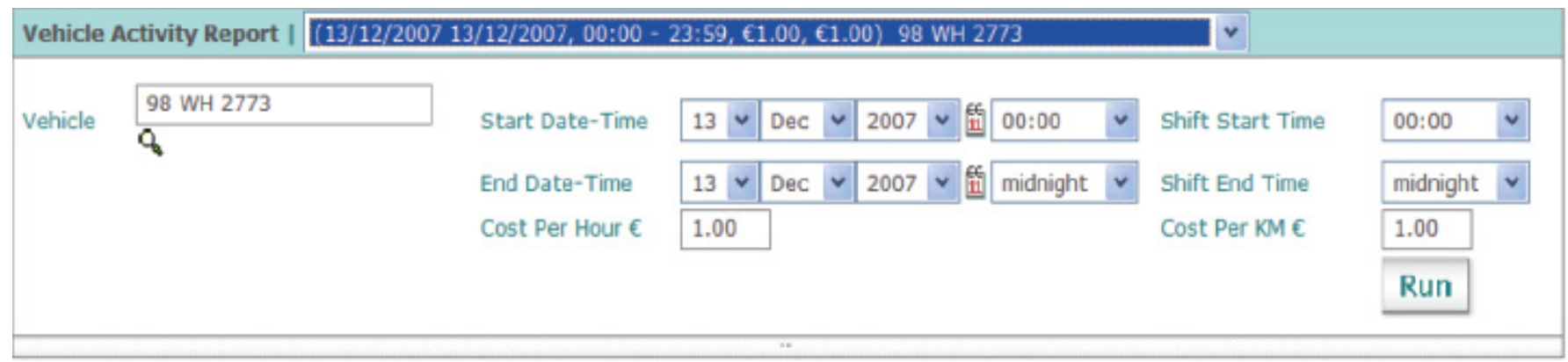

Report Summary | Requested by Kevin Conors

\section{Vehicle Activity Report}

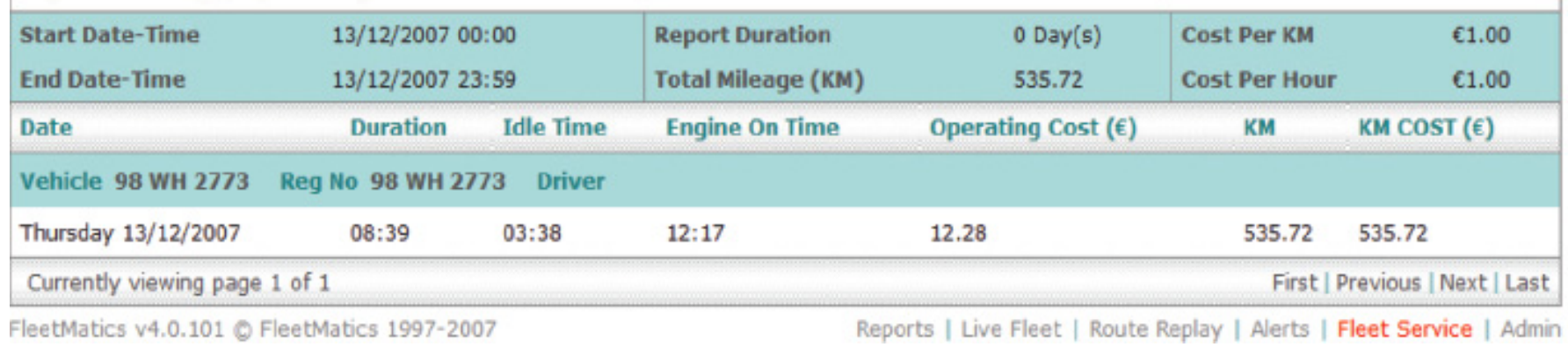

Fig. (8). Screenshot of Fleetmatics Vehicle activity report with CPK and CPH.

the respective transport manager to have an idea of realistic input values otherwise the usefulness of this calculating mechanism could be seriously mis-interpreted from a costings perspective.

\section{RESULTS AND DISCUSSIONS}

\subsection{Economic Assessment}

The biggest and most important difference between both systems tested from an economic monitoring point of view revolves around the recording of engine diagnostics. Bluetree offers an advanced aspect which involves connecting into the FMS of each truck and recording valuable engine diagnostic information such as accurate fuel data, fuel used, kilometer per gallon (kmpg), amount of fuel in diesel tank, harsh braking, over speeding, maximum revs per minute (rpm) and idling etc. Bluetree can connect to all any FMS of any truck manufacturer's engine so there are no limits to recording the engine and driver performance data.

The ability to monitor the fuel in the tank is a massive bonus for employers who are suspicious of employees perhaps siphoning diesel for their own use if they are able to take the truck home. The Bluetree system will record exact amount of litres of diesel in the tank, this figure can be checked once the truck has finished the days work. If, on restarting the truck the next morning there is a discrepancy in the amount of diesel without the truck having actually traveled anywhere then the most obvious and logical assumption is that diesel is being siphoned from the tank for use elsewhere by the driver in question. Being able to crack down on this abuse of resources would be an automatic money saving tactic, especially in today's markets where diesel fuel alone is the biggest expense for transport companies.

Taking this into account, this next example really showed the true money saving potential of monitoring the fuel information from the Bluetree system. By simply monitoring 2 different trucks it was discovered that the driver and engine performance increased dramatically. Initial average variations in mpg ranged from $7.5 \mathrm{mpg}$ to $8.5 \mathrm{mpg}$ mainly due to the fact that;

1. Some drivers could drive certain trucks more efficiently than other truck models,

2. There may have been situations of overloading, hence increased fuel consumption

3. There were situations of travelling empty which implies reduced fuel consumption.

To visualize the real impact of this technique the following working example is used;

For an articulated truck driving an average distance of $100000 \mathrm{~km} /$ annum -

Average mileage from system $=7.5 \mathrm{mpg}=2.66 \mathrm{~km} / \mathrm{L}(1$ $\operatorname{mpg}=0.3540062 \mathrm{~km} / \mathrm{L}$ )

$7.5 \mathrm{mpg}=12.07 \mathrm{kmpg}(2.66 * 4.54609)$

$100,000 \mathrm{~km} / 12.07 \mathrm{kmpg}=8,285.00$ gallons

$\Rightarrow \quad 8,285.00 * 4.54609=37,664$ litres

$\Rightarrow \quad 37,664$ litres $* 0.8 € /$ litre $=€ 30,131.20$

$\Rightarrow \quad \mathrm{CO}_{2}$ Emissions $=37,664 \mathrm{~L} * 2.67 \mathrm{~kg}=100,562.88 \mathrm{~kg}$ $=100.56$ Tonnes 
Table 1. Costings of Both Bluetree and Fleetmatics Fleet Asset Tracking

\begin{tabular}{|c|c|c|}
\hline & BLUETREE & FLEETMATICS \\
\hline GPS tracker unit & $€ 1,300$ & $\begin{array}{c}€ 2,400 \text { (all in price) Optional lease agreement of } € 15 / \text { truck/wk } \\
\text { for } 4 \text { years }=€ 2,880\end{array}$ \\
\hline FMS engine diagnostics & $€ 300$ & NA \\
\hline Truck manufactured FMS & $€ 300-€ 500$ & NA \\
\hline Live and Historic tracking & $€ 55 /$ annum & NA \\
\hline $\begin{array}{l}\text { Live and Historic tracking PLUS engine } \\
\text { diagnostics }\end{array}$ & $€ 90 /$ annum & NA \\
\hline Monthly GPRS data charge with O2 & Approx $€ 10$ per $4 \mathrm{Mb}$ of data transfer & NA \\
\hline Web Hosting and Software Licence & $€ 1300 /$ annum & NA \\
\hline TOTAL & $€ 3986.20$ (inc VAT @ 21\%) & $€ 2,400 / € 2,880$ (inc VAT @21\%) \\
\hline
\end{tabular}

For increase in fuel mileage to approximately $8.5 \mathrm{mpg}$ (reduction in fuel consumption)

Average mileage from system $=8.5 \mathrm{mpg}=3.01 \mathrm{~km} / \mathrm{L}$ $(1 \mathrm{mpg}=0.3540062 \mathrm{~km} / \mathrm{L})$

$8.5 \mathrm{mpg}=13.68 \mathrm{kmpg}($ kilometres per gallon $)(3.01 *$ 4.54609)

$100,000 \mathrm{~km} / 13.68 \mathrm{kmpg}=7,309.94$ gallons

$\Rightarrow \quad 7,309.94 * 4.54609=33,231.65$ litres

$\Rightarrow \quad 33,231.65 * 0.8 € /$ litre $=€ 26,583.32$

$\Rightarrow \quad \mathrm{CO}_{2}$ Emissions $=33,231.65 \mathrm{~L} * 2.67 \mathrm{~kg} / \mathrm{L}=$ $88,728.51 \mathrm{~kg}=88.73$ Tonnes

$\Rightarrow \quad$ Money Saving $=€ 30.131 .20-€ 26,583.32=$ $€ 3,547.88$

$\Rightarrow \quad \mathrm{CO}_{2}$ Emission Saving $=100.56 \mathrm{~T}-88.73 \mathrm{~T}=11.73$ Tonnes

SAVING approx $€ 3,500 /$ annum/truck on diesel fuel and 11.73 Tonnes of $\mathrm{CO}_{2}$ Emissions simply by decreasing fuel consumption by $1 \mathrm{mpg}$ due to increased driver performance. Table 1 shows the capital costs of both systems.

\section{CONCLUSIONS}

The overall objective of GPSTRACK was to use GPS technology in helping to improve transport logistics and reduce costs in the Irish timber haulage sector. The work is a significant step in the overall integration of Information Technology into the Irish forest industry. Specifically, the work, carried out in collaboration with industry and the Forest Industry Transport Group (FITG) has assessed the potential for the use of GPS asset tracking devices from an economic perspective, and to portray expert recommendations regarding their usefulness in timber haulage. From this paper, results have been used to determine the effectiveness and usefulness of such GPS tracking devices as a means of monitoring real-time drop off and pick up locations, monitoring the security of exact loads, trucks and drivers with detailed underlying road map detail and deciphering engine diagnostic recordings to fully optimize the operational running of each truck and in turn provide possible savings of approximately $€ 10,000$ per annum per truck on diesel fuel alone. Skogforsk, the
Swedish Research Forest Institute have published many articles on the idea of optimal and integrated logistics of timber haulage including work on Central Tyre Inflation (CTI) projects to minimize internal and public road damage and increase access to forests during the spring thaw and help decrease transport costs for roads with reduced passability [17]. The TRANSMIT project showed that better EcoDriving (driver training) reduced fuel consumption across designated reference roads up to $15 \%$. From TRANSMIT, Forsberg et al. 2003 [18] concluded that the quality of the road is crucial for improved eco-driving. The worst roads caused 25 to $40 \%$ higher fuel consumption. Future work will involve calculating the Root Mean Square (RMS) horizontal accuracy of the X and Y GPS tracklog data in relation to the underlying public road network and the internal forest road network in order to quantify the presence of any significant RMS error [19]. Bergstorm et al. 2000 [20] developed a software program that uses GIS to analyse the benefits of new forest roads based on what stands are to be harvested. The maps produced help the user to identify areas where new roads are needed from a routing perspective. This sort of research is an area where Ireland's timber and transport sector plans to follow. Other work will perhaps involve attempting to optimise the route scheduling of timber trucks in terms of revenue per $\mathrm{km}$ versus cost per $\mathrm{km}$ and incorporating in-car satellite navigation systems such as a Garmin Nuvi 770 for the truck drivers in question so that $\mathrm{X}$ and $\mathrm{Y}$ co-ordinates of all entry and exit points of forest properties can be uploaded accordingly based on the area of timber harvesting and thus, the sat-nav can route the driver to its exact destination in the forest and subsequent destination to the harvesting mills.

\section{ACKNOWLEDGEMENTS}

The GPSTRACK project was funded by Coford (National Council for Forest Research and Development) and the NDP.

\section{REFERENCES}

[1] Coford, "Forecast of Roundwood Production from the Forests of Ireland 2001-2015", 2001.

[2] Coillte, "Annual Report", 2003.

[3] G. Mintsis, S. Basbas, P. Papaioannou, C. Taxiltaris, and I. N. Tziavos, "Applications of GPS technology in the land transportation system”, Eur. J. Oper. Res., vol. 152, pp. 399-409, 2004. 
[4] R. Zito, G. D'Este, and M. A. P. Taylor, "Global positioning systems in the time domain: How useful a tool for intelligent vehicle highway systems?", Transp. Res. Part C, vol. 3, no. 4, pp. 193-209, 1995.

[5] G. J. Devlin, K. McDonnell, S. Ward, "Timber Haulage in Ireland: An Analysis using GIS and GPS", J. Transp. Geogr., vol. 16, no. 1, pp. 63-72, 2007.

[6] G. Murphy, "Reducing trucks on the road through optimal route scheduling and shared log transport services", South. J. Appl. For., vol. 27, no. 3, pp. 198-205, 2003.

[7] T. P. McDonald, S. E. Taylor, R. B. Rummer, and J. Valenzeula, "Information needs for increasing log transport", Proceedings of the first international precision forestry co-operative symposium, Seattle, Washingtion, June 21-2, chapter 24, 2001.

[8] Irish Department of Transport (DOT), Available from: www.gometric.ie [Accessed: June 2005].

[9] UK Timber Transport Forum - http://www.fidc.org.uk/timber transport. [Accessed: February 2005].

[10] G. J. Devlin, K. McDonnell, S. Ward, "Development of a spatial decision support system (SDSS) for route costing calculations within the Irish timber haulage sector", Trans. ASABE, vol. 51, no. 2, pp. 763-773. 2008.

[11] P.M.O. Owende, A.M. Martin, M.J. O'Mahony, and S.M. Ward, "Effect of logging traffic on forest access roads with peat substrates", Forestry Engineering for Tomorrow Conference Paper no. 6. June $28^{\text {th }}-30^{\mathrm{TH}} 1999$ Edinburgh University, Edinburgh, Scotland, 1999.
[12] A. M. Martin, P.M.O. Owende, N.M. Holden, S.M. Ward, and M.J O' Mahony, "Designation of timber extraction routes in a GIS using road maintenance cost data", J. For. Products, vol. 51, no. 10, pp. 32-38, 2001.

[13] Per-Åke Arvidsson, "Optimised route planning-good for both profits and the environment", Skogforsk, Resultat no. 23, 1998.

[14] M. Forsberg, "Cost-effective roundwood haulage", Skogforsk, Resultat no. 12, 2003.

[15] M. Frisk, and M. Ronnqvist, "Flowopt-a means of optimizing wood flow logistics", Skogforsk, Resultat no. 1, 2005.

[16] J. Eriksson, and M. Ronnqvist, "Transportation and route planning, Akarweb-a web based planning system", Proceedings of the $2^{\text {nd }}$ Forest Engineering Conference, Vaxjo, Sweden, May 12-15, pp. 48-57, 2003

[17] P. Granlund, "CTI on roundwood haulage vehicles", Skogforsk, Resultat no. 3, 2006.

[18] M. Forsberg, and C. Lofroth, "IT-study in four haulage rigs brings greater fuel economy with training and better roads", Skogforsk, Resultat no.1, 2003.

[19] S. E. Taylor, T. P. McDonald, M. V. Veal, and T. E. Grift, "Using GPS to evaluate the productivity and performace of forest machine systems", Proceedings of the first international precision forestry co-operative symposium, Seattle, Washingtion, June 21-20, chapter 19, 2001.

[20] J. Bergstrom, and F. W. Dianthus, "GIS based benefits analysis of new forest truck roads", Skogforsk, Resultat no. 23, 2000.

(C) Devlin and McDonnell; Licensee Bentham Open.

This is an open access article licensed under the terms of the Creative Commons Attribution Non-Commercial License (http://creativecommons.org/licenses/by$\mathrm{nc} / 3.0 /$ ) which permits unrestricted, non-commercial use, distribution and reproduction in any medium, provided the work is properly cited. 